\title{
Eticiência do Trabalhador: Uma Nova Fórmula
}

\author{
Connélio Octavio Pinheiro Pimenta
}

bjetiva o presente trabalho apresentar uma nova fórmula que expresse melhor os fatôres responsáveis pela eficiência de um trabalhador industrial em substituição à dos professôres norteamericanos AlLEN \& RichaRds, que é a seguinte:

$$
\begin{aligned}
& \mathrm{E}=\mathrm{f} \text { (M.T,I,J,MO) } \\
& \text { ou seja, eficiência seria função de: } \\
& \mathrm{M} \text { - habilidade manual } \\
& \text { T - conhecimentos tecnológicos } \\
& \text { I - outros conhecimentos correlatos } \\
& \text { J - senso de julgamento } \\
& \text { MO - motivação }
\end{aligned}
$$

2. A nova fórmula, que ora apresentamos, é fruto de uma pesquisa que, conjuntamente com o Professor Antônio Ferreira de Andrade, do Instituto de Pesquisas da Fundação Universidade do Trabalho de Minas Gerais - UTRAMIG -, realizamos nas oficinas mecânicas das indústrias metalúrgicas mineiras, Comparhia Belgo Mineira (João Monlevade), ACESITA e USIMINAS (Ipatinga), por determinação do Professor Agnelo Corrêa Vianna, Reitor da referida Fundação.

3. Em cada uma dessas indústrias metalúrgicas procuramos observar, detida e minuciosamente, o trabalho de diversos torneiros, na execução de variados serviços em máquinas diferentes, com o uso de fôlhas de anotações e relógios, complementados por entrevistas com os seus supervisores.

4. Em conseqüência do que foi observado, verificamos, nìtidamente, que a fórmula AlLEN \& Richards é insuficiente para explicar as causas que intervêm na eficiência global de um trabalhador, já que omite alguns fatôres que, em maior ou menor grau, influenciam, decididamente, na referida eficiência.

5. Por isso idealizamos - com base na pesquisa que efetuamos, e em nossa vivência administrativa - a seguinte fórmula, -aplicável a qualquer das funções existentes nas indústrias, desde 
a mais elevada na hierarquia, até a mais baixa (e mesmo a diversas. profissões não industriais):

$$
\mathrm{E}=\mathrm{A}+\mathrm{E} \pm \mathrm{F}+\mathrm{G}+\mathrm{H}+\mathrm{I}+\mathrm{P}+\mathrm{S}
$$

6. Por certo variará, de acôrdo com os cargos exercidos, o grau de intensidade exigido de cada um dos fatôres da fórmula, mas cremos que todos êles se manifestam em maior ou menor escala. Analisemos, agora, a fórmula proposta.

7. $E$ significa, evidentemente, a eficiência, que seria a soma dos seguintes fatôres:

$7.1 A$ é o fator ADMINISTRATIVO, que na fórmula Allen \& Richards corresponde ao fator J (Judgement). Podemos, a respeito, distinguir a "administração-endógena", e a "administração-exógena." A primeira corresponderia àquelas características do trabalhador necessárias, em maior ou menor grau e conforme as funções a exercer, à eficiência do trabalho, tais como planejá-lo e organizá-lo antes de executá-lo e a controlá-lo após a execução, a fim de verificar se saiu como se esperava. A segunda seria o fator exógeno, independente do trabalhador, mas não do trabalho em si, razão pela qual influi na sua eficiência. Corresponderia ao planejamento, organização e contrôle do trabalho pela chefia ou por órgãos especializados, cabendo ao trabalhador sòmente a execução "tout court" que, mesmo nestes casos, nunca dispensa a "auto-administração", ainda que em mícomumente, receba planejada a tarefa e o contrôle da qualidade do trabalho executado se efetue também por outro empregado, terá sempre que procurar a máquina, planejar as sucessivas seqüências do seu trabalho e, finalmente, êle mesmo, antes de entréde qualidade". medindo a e verificando se ela está dentro das medidas constantes do desenho recebido.

7.2 $E$ fator ESPECIALIZAÇAOO. São os conhecimentos especializados requeridos para a boa execução de qualquer trabalho. Corresponde ao fator $T$ (technology) da fórmula AlLEN \& Richards. Cada tarefa tem seus seqredos, seus "pontos chave", como se diz no "T.W.I.", que podem ser ministrados, com suenso, através de instruções orais e escritas. Muitos se surpreda profissão, algur que, mesmo conhecendo as técnicas especificas É que, como alguns empregados não usam ou as empregam mal. ciência de um estamos vendo, os fatôres que determinam a efichoque.

$7.3 \mathrm{~F}$ fato FISIOLógiCO. Na fórmula Allen \& RICHARDS encontramos o fator $\mathrm{M}$, que corresponderia à habilidade 
manual. Achamo-lo restrito, razão pela qual resolvemos ampliá-lo e cognominá-lo fator fisiológico. Realmente, mesmo nas profissões que exigem ampla e hábil destreza das mãos, como, por exemplo, na de torneiro, outras partes do corpo intervêm no trabalho, tais como os braços, a visão, etc. Há funções que pedem fôrça muscular acentuada, como as exercidas pelos carregadores no serviço de carga e descarga, sendo solicitados músculos de várias partes do corpo, tais como os bíceps, trapézios, deltóides, etc.

Os esportistas exigem, em seu labor, o uso de diversos órgãos do corpo. Certas profissões femininas, como a de manequim e a de recepcionista, exigem certos atributos anatômicos (beleza, magreza, altura, etc.).

Parte do fator fisiológico é inato e parte depende do contínuo adestramento.

7.4 G fator GENERALIZAÇÃO, que, na fórmula Allen \& Richards - embora, ao nosso ver, de maneira mais restrita, está expresso no fator I (relaced instruction). E a cultura geral, básica, cuja importância nem sempre é levada na devida consideração. Realmente, pretender dar a um empregado conhecimentos especializados e cultura técnica sem que, preliminarmente, tenha êle uma sólida cultura geral humanística, é o mesmo que se desejar levantar as paredes de uma casa sem o adequado alicerce.

Recentes estudos realizados na U.R.S.S. comprovaram a grande correlação existente entre o ensino escolar e a produtir vidade do trabalhador. A fls. 71 e 72 da publicação da UNESCO, editada em 1965, e intitulada "Aspectos Sociales y Economicos del Planeamiento de la Educación", no capítulo III - Aspecto economico de la Academia de Ciências de Moscú, encontramos o seguinte e expressivo trecho: "La Comisión $\mathrm{Na}$ cional de Planeamiento (GOSPLAN) estudió un proyeto de desarrollo del sistema escolar en diez años destinado a implantar la enseñanza gratuita y obligatoria para todos los niños, comenzando por cuatro años de enseñanza primaria. Los especialistas de GOSPLAN comenzaron a estudiar entonces atentamente el rendimento economico de las inversiones escolares.

El examen de los salarios y la produtividad de diferentes categorias de obreros y de empleados, en relación con su grado de instrucción, nos ha elevado a la conclusión de que la enseñanza escolar incluso la más elemental, es mucho más provechosa para un trabajador, que un largo aprendizaje en el taller. Para esos cálculos, tuvimos en cuenta las consecuencias de varios factores como la edad, la experiencia profisional, la competencia técnica, etc. Por ejemplo, la instrucción rudimentaria que se adquire en un año de enseñanza primaria aumenta la produtividad de un trabajador en un $30 \%$ por término médio en tanto que el 
aumento de la competencia y el aumento de producción de un, trabajador analfabeto resultante de un periodo semejante de aprendizaje en fabrica, no és más que del 12 al $16 \%$ anual. El aumento de capacidad profesional que resulta de un año de escolaridad y por término médio, 2,6 veces mayor que el que se obtiene como consecuencia de un año de aprendizaje. Después de cuatro años de enseñanza primaria, la producción y el salario de un obrero son superiores en un $79 \%$ a los de un trabajador de primera categoria que no ha ido a la escuela. Después de siete años de estudios (ciclo secundario corto), la calificación de un empleado de oficina puede ser $235 \%$ superior a la del nivel nuás bajo; después de nueve años de estudios (ciclo secundario completo), puede llegar al $280 \%$ superior; y puede ser de un $320 \%$ después de trece o catorce años de estudios, basta enseñanza superior."

A transcrição acima nos mostra a importância do fator $G$ na eficiência de um empregado, embora seja oportuno salientar que - ensino escolar não fornece ao futuro trabalhador apenas os conhecimentos de que trata o referido fator, e por isso mesmo, tâo expressivas são as cifras percentuais contidas no estudo supratranscrito. No ambiente escolar, a criança e o jovem têm melhores rondições de plasmar as suas personalidades, de desenvolver as stuas inteligências e de adquirir uma sólida formação moral e um forte senso de responsabilidade, do que no ambiente fabril. Constituem fatôres que nossa fórmula contém, e que adiante examinaremos.

$7.5 H$ fator HIGIDEZ. A saúde, quer física ou mental, é fator de importância na eficiência do empregado. Além_dos casos graves, em que se torna necessário aposentar prematuramente o trabalhador, ou licenciá-lo por longos períodos, com re: flexos nos custos da produção, também os mais leves influem, e, já agora diretamente na eficiência do profissional, de vez que permanece em serviço, mas seu rendimento decai sensivelmente. São os casos de certos desânimos, apatias, angústias, neuroses, depressões, etc. Distingue-se do fator fisiológico, já que neste levamos em conta as características anatômicas adequadas à profissão. Um trabalhador que, constantemente, emprega a fôrça muscular, necessita possuir músculos bem desenvolvidos. Naquele é a saúde dos órgãos que se tem em mira. No exemplo dado o trabalhador em questão, apesar de possuir os músculos adequados ao trabalho, pode se achar gripado e ver suas fôrças normais diminuírem sensivelmente. O reverso pode ocorrer: possuir o empregado excelente saúde, mas não ter as características fisiológicas solicitadas pelo cargo, quando, então, sua eficiência é sempre pré
cária.

7.6 I fator INTELIGENCIA Embora varie sua importância, conforme o tipo do trabalho a ser executado, é um fator 
sempre presente. Quase nulo, mas não totalmente nulo, em certas funções, em outras adquire excepcional preponderância. Pesquisás científicas conhecidas revelaram que a hereditariedade desempenha forte papel no nivel da inteligência, mas mostraram também que o ambiente escolar, social e familiar podem desenvolvê-la ou atrofiá-la, em parte. Para o objetivo a que visamos, a inteligência é aqui conceituada em um sentido lato, bastante amplo. Quer o trabalho exija apenas memória, ou rapidez de raciocinio, ou atenção, concentração, abstração ou espírito inventivo; habilidade em efetuar operações matemáticas simples ou complexas etc., em todos êstes exemplos, tais exigências são catalogadas no fator I.

\section{7 $P$ fator PERSONALIDADE. Na fórmula AlLEN $\mathcal{E}$} RICHARDS encontra-se o fator MO (o Moral, a Motivação). Preferimos desdobrá-lo em dois: fator PERSONALIDADE e fator SOCIAL. Chamá-lo simplesmente de "moral", significa apresentar o efeito e não, as causas motivadoras do moral elevado, no trabalho.

Realmente, quando observamos um empregado dedicado, entusiasmado, satisfeito, caprichoso na execução de suas tarefas, disciplinado etc., o fator personalidade (e o fator social que veremos a seguir) é uma das causas de tais atitudes perante o trabalho que, como é óbvio, exercem grande influência na eficiência de qualquer tipo de tarefa.

Por personalidade, queremos dizer aquêles traços psicológicos inatos, sôbre os quais os fatôres sociais irão trabalhar positiva ou negativamente. Mas, assim como em terra ruim uma boa semente não se transforma em bela árvore, também, mesmo lançada em terra fértil, uma semente defeituosa, se vingar, será apenas uma árvore raquítica.

$7.8 \mathrm{~S}$ fator SOCIAL. Em várias profissões constituiu um dos fatôres mais importantes. Aqui acha-se o caráter, a formação moral, o senso de responsabilidade, a adequada escala de valôres, enfim, tôdas aquelas características mentais que os pais, os professôres, colegas, chefes, dirigentes, o meio e a estrutura social se incumbem de fixar no trabalhador e que irão exercer, por vêzes, extraordinária influência em sua conduta na vida, e na sua eficiência no trabalho.

Em têrmos "freudianos", diriamos que o fator personalidade é o EGO, e o fator social o SUPER-EGO, ou, em têrmos "durckheiminianos", que o primeiro conteria a consciência individual, e o segundo a consciência social.

Ao finalizarmos, queremos agradecer ao Professor Agnelo Corrêa Vianna que, ao determinar a realização da pesquisa que nos serviu de base a êste estudo, bem compreendeu a necessidade de se procurar partir da observação sistemática e cuidadosa dos 
fatos, para, sôhre êles, idealizar-se fórmulas, ou elaborar-se princípios e leis de caráter científico.

Ao Professor Antônio Ferreira de Andrade, nosso companheiro na pesquisa realizada e de quem recebemos valiosas sugestǒes, e que conosco dividiu a penosa tarefa de colhêr os dados llas indústrias visitadas, nosso profundo agradecimento.

Às indústrias metalúrgicas, Companhia Belgo Mineira, Companhia de Aços Especiais Itab:ra - ACESITA, Usina Sịderúrgica Minas Gerais - USIMINAS, que tão gentilmente nos acolheram e nos proporcionaram tôdas as facilidades para a boa execucão da pesquisa efetuada em suas Oficinas Mecânicas, nosso muito obrigado.

Esperamos que a fórmula proposta seja debatida por todos aquêles que se interessam pelo progresso industrial, através da elevação da eficiência dos empregados. Não esperamos seja ela perfeita nem definitiva. Outras, mais aperfeiçoadas, surgirão. De nossa parte, continuaremos pesquisando e meditando. Somos dos que acham que o progresso humano, ainda longe, muito longe se acha de seu limite, se é que um dia o alcance. 